Synt hesi s of ferromanet i c Bi-subst i t ut ed yttriumiron garnet fil ns by laser abl ation

\begin{tabular}{|l|l|}
\hline 著者 & K doh Hi deo, Mri mot o Aki har u, Shi m zu Tast uo \\
\hline 著者別表示 & 森本 章治, 清水 立生 \\
\hline $\begin{array}{l}\text { j our nal or } \\
\text { publ i cat i on ti t l e }\end{array}$ & Appl i ed physi cs I et ter s \\
\hline vol une & 59 \\
\hline nunber & 2 \\
\hline page range & $237-239$ \\
\hline year & $1991-07-01$ \\
\hline URL & ht t p: //doi . or g/10. 24517/00010081 \\
\hline
\end{tabular}




\title{
Synthesis of ferromagnetic Bi-substituted yttrium iron garnet films by laser ablation
}

\author{
Hideo Kidoh, Akiharu Morimoto, and Tatsuo Shimizu \\ Department of Electronics, Faculty of Technology, Kanazawa University, Kanazawa 920, Japan \\ (Received 25 March 1991; accepted for publication 2 May 1991) \\ Bismuth-substituted yttrium iron garnet (Bi:YIG) films were deposited on gadolinium \\ gallium garnet substrate by laser ablation using the ArF excimer laser. This is the first report \\ on the preparation of Bi-substituted YIG films by laser ablation. Films have a garnet \\ single phase above the substrate temperature of $490^{\circ} \mathrm{C}$, and the film composition does not \\ deviate largely from the target composition and it is almost constant in the \\ temperature range between 490 and $580^{\circ} \mathrm{C}$. The saturation magnetization of the film is 1500 \\ $\mathrm{G}$ at room temperature. Faraday rotation angle $\theta_{F}$ at a wavelength of $830 \mathrm{~nm}$ at room \\ temperature is $-0.3 \times 10^{4} \% \mathrm{~cm}$.
}

Rare-earth iron garnet (RIG) films are of great interest in device applications such as magneto-optical memory device and waveguide optical isolator, because of its transparency in near-infrared region and excellent magneto-optical properties such as anomalously large Faraday rotation angle in the region from visible to near infrared. Especially in yttrium iron garnet (YIG), Faraday rotation angle $\theta_{f}$ at a wavelength of $633 \mathrm{~nm}$ at $295 \mathrm{~K}$ is $+835^{\circ} \%$ $\mathrm{cm} .{ }^{1} \mathrm{An}$ increase in the amount of $\mathrm{Bi}$ substituted for $\mathrm{Y}$ makes Faraday rotation angle change linearly at a rate of $-2.1 \times 10^{4} \% \mathrm{~cm}$ (1 Bi atom/f.u.), where f.u. represents formula unit. In fully Bi-subetituted iron garnet $\left[\mathrm{Bi}_{3} \mathrm{Fe}_{5} \mathrm{O}_{12}:(\mathrm{BIG})\right], \theta_{F}$ of greater than $-6.2 \times 10^{4} \% \mathrm{~cm}$ can be expected. Moreover, the incorporated $\mathrm{Bi}$ ions do not reduce the transparency of the film. Therefore, Bi-substituted YIG (Bi:YIG) films attracts a great attention from the viewpoints of both materiais science and applications. For use in magneto-optical memory devices, the films are required to have magnetic anisotropy perpendicular to the film plane. In many cases, films have been epitaxially deposited on (111) plane of paramagnetic garnet substrate because $\langle 111\rangle$ axis of these ferromagnetic garnet materials is the axis of easy magnetization. Conventionally, Bi:YIG films have been prepared by liquid phase epitaxy (LPE), ${ }^{2}$ reactive ion beam sputtering (RIBS), ${ }^{3,4}$ and rf-magnetron sputtering. 5,6 These methods, however, have some disadvantages such as the problems of impurity admixture, low deposition rate, and large fluctuation in composition, respectively.

On the other hand, it has been indicated that laser ablation has great advantages in preparing multielement oxide thin films such as superconducting thin films and ferroelectric thin films. ${ }^{7-9}$ The most promising characteristics of this preparation method are the following: (1) Even materials with a high melting-point can be easily deposited if the materials strongly absorb the laser light. (2) Deposition in high oxygen pressure is possible because of the absence of energy sources in the system. (3) There is little difference in the composition between the target material and the deposited film. So far, our group has prepared $\mathrm{Ba}-\mathrm{Y}-\mathrm{Cu}-\mathrm{O}$ superconducting thin films ${ }^{10,11}$ and lead-zirconate-titanate (PZT) ferroelectric thin films ${ }^{12,13}$ with the excellent properties using laser ablation. Considering these features, Bi:YIG film, which is a multielement oxide ferromagnetic thin film, is expected to be successfully prepared by laser ablation.

In this letter, we report the results of the structural and ferromagnetic properties of Bi:YIG films prepared by laser ablation using the ArF excimer laser.

Details of the equipment for the preparation of Bi:YIG films are almost the same described in a previous letter. ${ }^{2}$ The substrate is heated up by focusing the infrared ray emitted from the lamp exterior to the vacuum chamber. The film deposition was carried out by the ablation of a Bi:YIG ceramic target in the vacuum chamber with an oxygen gas pressure of 27-133 Pa using an ArF excimer laser (Shibuya SQL2240, $193 \mathrm{~nm}$ wavelength, $10 \mathrm{~ns}$ pulse width, $5 \mathrm{~Hz}$ repetition rate). The ceramic target is a pellet of $\mathrm{Bi}_{1.5} \mathrm{Y}_{1.5} \mathrm{Fe}_{5} \mathrm{O}_{12}$. In order to ablate always the fresh target surface, the target was continuously moved during the film deposition. A (111) plane of gadolinium gallium garnet $\left[\mathrm{Gd}_{3} \mathrm{Ga}_{5} \mathrm{O}_{12}:(\mathrm{GGG})\right]$ was used as a substrate. The distance from the target to the substrate is about $30 \mathrm{~mm}$. The substrate temperature, measured by thermocouple on the substrate surface and radiation thermometer, was controlled between 200 and $580^{\circ} \mathrm{C}$. The laser energy for the ablation was $70 \mathrm{~mJ} / \mathrm{shot}$, which corresponds roughly to a laser fluence of $3.5 \mathrm{~J} / \mathrm{cm}^{2}$ shot. After the ablation, films were cooled to room temperature in $3 \mathrm{~h}$ : X-ray diffraction (XRD) measurements were carried out using $\mathrm{Cu} K \alpha$ to investigate the film structure. The film composition was measured by inductively coupled plasma spectroscopy (ICP). Film morphology was inspected using scanning electron microscopy (SEM). The measurement of Faraday rotation angle was carried out at a wavelength of $830 \mathrm{~nm}$. The ferromagnetic resonance (FMR) measurement was carried out at a frequency of $9.472 \mathrm{GHz}$ using Varian E-109 $X$-band spectrometer. These measurements were carried out at room temperature.

Typical film thickness is about $0.5 \mu \mathrm{m}$ and the film deposition rate is in the range of $0.7-1.3 \AA / \mathrm{s}$ at the preparation conditions mentioned above. The deposition rate is about five times larger than that for the RIBS ${ }^{14}$ and the same as that for the rf-magnetron sputtering. ${ }^{5}$ 


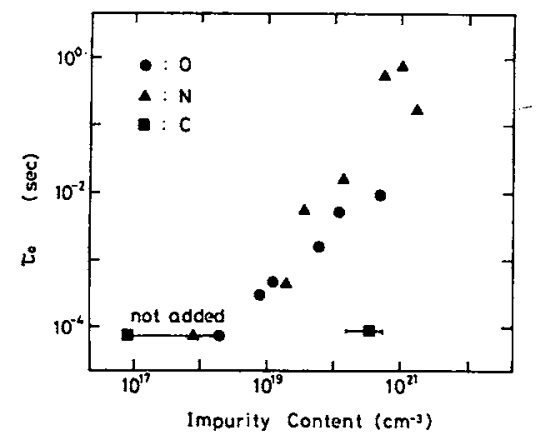

FIG. 4. Decay time $\tau_{0}$ as a function of $O, N$, and $C$ contents.

thought to result from the upward shift of $E_{F}{ }^{10}$ For the N incorporation, $\sigma_{F}$ increases with the $\mathrm{N}$ content from $10^{-5}$ to $10^{-3} \mathrm{~S} / \mathrm{cm}$, while $\sigma_{d}$ from $10^{-10}$ to $10^{-6} \mathrm{~S} / \mathrm{cm}$. For the $O$ incorporation, $\sigma_{d}$ increases with the $O$ content from $10^{-10}$ to $10^{-4} \mathrm{~S} / \mathrm{cm}$, while $\sigma_{d}$ increases from $10^{-10}$ to $10^{-8} \mathrm{~S} / \mathrm{cm}$. Therefore, the photosensitivity $\sigma_{p} / \sigma_{d}$ decreases from $10^{5}$ to $10^{3}$ for the $\mathrm{N}$ incorporation, and from $10^{5}$ to $10^{4}$ for the $O$ incorporation.

The results of light-induced ESR measurements at 77 $\mathrm{K}$ also show that the density of charged dangling bonds increases with an increase in the $O$ and $N$ contents, whereas the density of neutral dangling bonds remains unchanged. The results of the measurement of optical absorption due to defects using the constant photocurrent method (CPM) also suggest the increase in the density of charged dangling bonds.

Finally, the photocurrent decay from the steady state after the switching-off of the steady illumination was investigated. We define a decay time $\tau_{0}$ as a time when the photoconductivity $\sigma_{P}(t)$ decays to $1 / e$, where the steady state $\sigma_{P}$ is fixed to be $1 \times 10^{-6} \mathrm{~S} / \mathrm{cm}$ by changing the illumination intensity. ${ }^{3}$ Figure 4 shows the decay time $\tau_{0}$ as a function of the impurity content. It is revealed that the $\mathrm{N}$ incorporation dramatically increases $\tau_{0}$ by 4 orders, and the $O$ incorporation by 2 orders. Such a degradation in the photoresponse should be suppressed for the application to $a$-Si:H optical sensor devices which need a rapid response. The degradation of the photoresponse shows a formation of a new trap state below the conduction band by the $\mathrm{N}$ or $O$ incorporation.
The present results mentioned above are reasonably explained in terms of the following model. ${ }^{1}$ Some of the $\mathrm{N}$ and $\mathrm{O}$ atoms incorporated in $\mathrm{a}-\mathrm{Si}: \mathrm{H}$ become fourfold-coordinated $\mathrm{N}_{4}^{+}$and threefold-coordinated $\mathrm{O}_{3}^{+}$, respectively, acting as a donor. According to our model, ${ }^{1}$ a photoexcited electron is captured at $\mathrm{N}_{4}^{+}$or $\mathrm{O}_{3}^{+}$, resulting in the bond breaking. Then $\mathrm{N}_{4}^{+}$or $\mathrm{O}_{3}^{+}$changes to $\mathrm{N}_{3}^{0}$ or $\mathrm{O}_{2}^{0}$, respectively, creating neutral $\mathrm{Si}$ dangling bonds $\mathrm{Si}_{3}^{0}$ at the neighboring site. ${ }^{3}$ This appears to be the origin of the light-induced ESR signals. The increase in $\tau_{0}$ due to the $N$ or $\mathrm{O}$ incorporation shown in Fig. 4 is attributed to a trapping of photoexcited electrons by $\mathrm{N}_{4}^{+}$or $\mathrm{O}_{3}^{+}{ }^{+}$Figures 2 and 3 indicate that the $\mathbf{N}$ incorporation increases both $\sigma_{\mathrm{d}}$ and $\tau_{0}$ more prominently than the $O$ incorporation. However, the increase in $\sigma_{d}$ by the $\mathbf{N}$ incorporation is far smaller than that by the $\mathbf{P}$ or As incorporation. ${ }^{5}$ Through the present study it is found that $\mathbf{C}$ atoms do not have a prominent effect in moving the Fermi level.

In summary, both $\mathrm{O}$ and $\mathrm{N}$ impurities were found to increase the dark conductivity by decreasing its activation energy in $a-\mathrm{Si}: \mathrm{H}$ films. Furthermore, it was found that both of them delay the photoresponse. $\mathrm{C}$ impurity, however, has no appreciable effect on them. These findings suggest that $\mathrm{O}$ and $\mathrm{N}$ impurities shift the Fermi level upward and form a trapping state for photoexcited electrons, supporting our $\mathrm{O}_{3}^{+}$and $\mathrm{N}_{4}^{+}$model. ${ }^{1}$

The authors are grateful to $\mathrm{S}$. Fujii for his technical assistance. This work was supported in part by the Sunshine Project of the Ministry of International Trade and Industry of Japan.

'T. Shimizu, H. Kidoh, A Morimoto, and M. Kumeda, Jpn. J. Appl. Phys. 28, 586 (1989)

${ }^{2}$ A. Morimoto, M. Matsumoto, M. Kumeda, and T. Shimizu, Jpn. J. Appl. Phys. 29, L1747 (1990)

${ }^{3}$ M. Kumeda, M. Yoshita, A. Morimoto, and T. Shimizu, Jpn. J. Appl. Phys. 29, L1578 (1990).

${ }^{4}$ K. Winer, R. A. Street, N. M. Johnson, and J. Walker, Phys. Rev. B 42, $3120(1990)$.

${ }^{5}$ M. Stutzmann, D. K. Biegetsen, and R. A. Street, Phys. Rev. B 35, 5666 (1987).

T. Shimizu, X. Xu, H. Kidoh, A. Morimoto, and M. Kumeca, J. Appl. Phys. 64, 5045 (1988).

${ }^{7}$ T. Noguchi, S. Usui, A. Sawada, Y. Kanoh, and M. Kikuchi, Jpn. J. Appl. Phys. 21, L485 (1982)

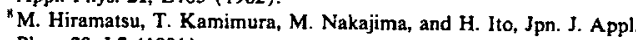
Phys. 30, L7 (1991).

${ }^{9} Y$. Hishikawa, M. Ohnishi, and Y. Kuwano, Mater. Res. Soc. Symp. Proc. 192, 3 (1990).

${ }^{10}$ E. Morgado, Philos. Mag. B 63, 529 (1991). 


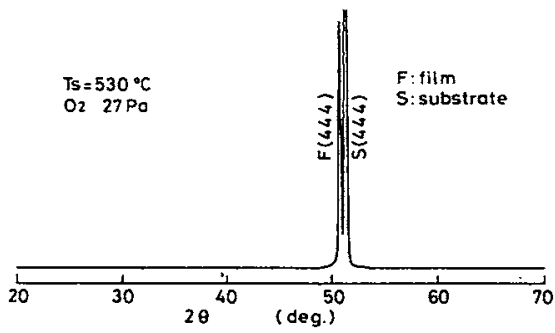

FIG. 1. XRD spectrum of the Bi:YIG film on GGG (111) plane prepared at $T_{\mathrm{s}}=530^{\circ} \mathrm{C}$ and oxygen pressure of $27 \mathrm{~Pa}$.

XRD spectrum of the Bi:YIG film on GGG(111) plane prepared at a substrate temperature of $530^{\circ} \mathrm{C}$ and an oxygen pressure of $27 \mathrm{~Pa}$ is shown in Fig. 1. Only the peak for the (444) plane of the Bi:YIG film is observed besides the peak for the (444) plane of GGG substrate. From this spectrum, it is confirmed that the film has a garnet single phase and $\langle 111\rangle$ axis, which is the axis of easy magnetization, is perpendicular to the film plane. At oxygen pressure of $27 \mathrm{~Pa}$, below the substrate temperature of $510^{\circ} \mathrm{C}$, all the films were found to be amorphous. When oxygen gas pressure increases to $133 \mathrm{~Pa}$, however, the film is crystallized and has a garnet single phase above $490^{\circ} \mathrm{C}$. The full width at half maximum (FWHM) of the (444) diffraction for the film prepared at the pressure of $133 \mathrm{~Pa}$ is slightly smaller than that for $27 \mathrm{~Pa}$. From these FWHM values, we estimated the crystallite size of these films to be about 1000 Å.

SEM photographs of the films prepared at the different conditions are shown in Fig. 2. In the case of the gas pressure of $133 \mathrm{~Pa}$, although droplets with submicron size exist on the film surface, the size of the grain in the film is

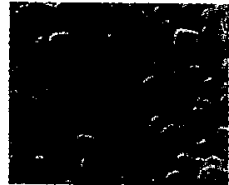

(a)

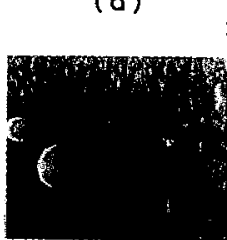

(c)

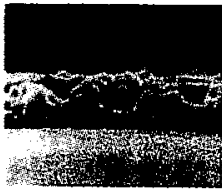

(b)

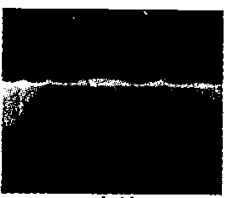

(d)
$\mathrm{Bi} Y \mathrm{YIG}$

GGG

Bi:YIG

GGG

FIG. 2. SEM photographs of the films. (a) and (b) show the film surface and the sectional view, respectively, of the fim prepared at $T_{s}=530^{\circ} \mathrm{C}$ and oxygen pressure of $27 \mathrm{~Pa}$. (c) and (d) show the film surface and the sectional view, respectively, of the film prepared at $T_{s}=510^{\circ} \mathrm{C}$ and oxygen pressure of $133 \mathrm{~Pa}$.

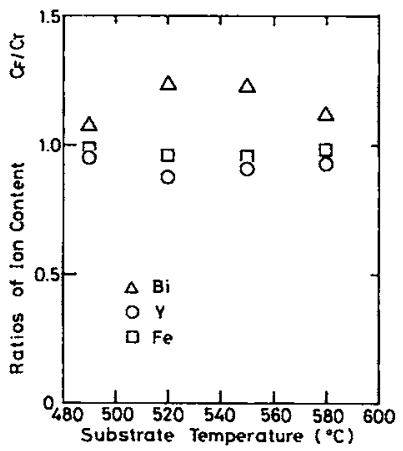

FIG. 3. Substrate temperature dependence of the ratio of the ion content in the film $\left(C_{F}\right)$ to those in the target $\left(C_{f}\right)$. Films were prepared at oxygen pressure of $133 \mathrm{~Pa}$.

uniform and the film surface is smooth in comparison with the case of the gas pressure of $27 \mathrm{~Pa}$. The smoothness of the film surface is important for employing these films in the magneto-optical devices. The sectional views also show that the film prepared at the pressure of $133 \mathrm{~Pa}$ has a uniform and dense structure. From the XRD measurement and the film morphology, it can be seen that the oxygen pressure of $133 \mathrm{~Pa}$ is suitable for preparing Bi:YIG films.

Ratios of the ion contents in the films $\left(C_{F}\right)$ to those in a target $\left(C_{T}\right)$ plotted as a function of substrate temperature at the oxygen pressure of $133 \mathrm{~Pa}$ are shown in Fig. 3. Although around $20 \%$ of excess $\mathrm{Bi}$ ions is found in the film, the film composition is roughly constant in the temperature range between 490 and $580^{\circ} \mathrm{C}$.

Figure 4 shows the magnetic field dependence of Faraday rotation angle of the film prepared at a substrate temperature of $510^{\circ} \mathrm{C}$ and the pressure of $133 \mathrm{~Pa}$. The measurement was carried out at $830 \mathrm{~nm}$ wavelength. At the magnetic field of about $2 \mathrm{kOe}$, the rotation angle becomes maximum and from this maximum value we obtain $\theta_{F}=-0.3 \times 10^{4} \% \mathrm{~cm}$. In this measurement, the polarized light reflected at the interface between the film and the

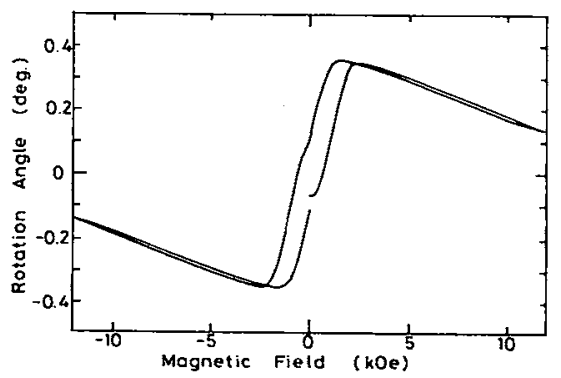

FIG. 4. Applied magnetic field dependence of Faraday rotation angle, measured at a wavelength of $830 \mathrm{~nm}$ at room temperature. Films were prepared at $T_{\mathrm{r}}=510^{\circ} \mathrm{C}$ and oxygen pressure of $133 \mathrm{~Pa}$. 
substrate was detected, so that the calculation was carried out by considering twice the film thickness as the light path.

The magnetization measurement revealed that the film has the axis of easy magnetization parallel to the film plane, in spite of the $\langle 111\rangle$ axis orientation perpendicular to the film plane. This is explained by the fact that the anisotropy field perpendicular to the film plane is overcome by the demagnetizing field $\left(4 \pi M_{s}\right)$ in the film. The saturation magnetization $\left(4 \pi M_{s}\right)$ is about $1500 \mathrm{G}$, which is similar to that for Bi:YIG film prepared by RIBS. ${ }^{14}$ From the magnetization and the ferromagnetic resonance (FMR) measurements, the anisotropy field is calculated to be $985 \mathrm{G}$ under an assumption of uniaxial isotropy. Considering these values of the anisotropy field and the demagnetizing field, it is expected that the films with a magnetic anisotropy perpendicular to the film plane can be obtained by reducing the saturation magnetization of the films. It is realized by substituting paramagnetic ions such as $\mathrm{Al}^{3+}$ or $\mathrm{Ga}^{3+}$ for $\mathrm{Fe}^{3+}$ in Bi:YIG.

In summary, Bi-substituted YIG films with a (111) orientation were successfully grown on the (111) plane of GGG substrate by laser ablation using the ArF excimer laser. The following results were obtained: (1) The saturation magnetization $\left(4 \pi M_{s}\right)$ of the film is about $1500 \mathrm{G}$ and Faraday rotation angle is $-0.3 \times 10^{4} \% \mathrm{~cm}$ at a wavelength of $830 \mathrm{~nm}$. (2) The film composition does not deviate largely from the target one, and it is almost constant in the substrate temperature range of $490-580^{\circ} \mathrm{C}$. (3) The oxygen gas pressure influences the crystallization temperature, film structure, and morphology. A relatively high oxygen gas pressure is suitable for preparing the garnet films.
We would like to thank Professor M. Kumeda of Kanazawa University for his many helpful discussions and Dr. T. Okuda of Electrotechnical Laboratory for helpful comments. We would also like to thank Dr. H. Fujiwara of the Tsukuba Research Laboratory, Hitachi Maxell Ltd. for the measurement of Faraday rotation angle. We would also like to thank $H$. Yashima for his help in our experiments. We are grateful to Shibuya Kogyo Co., Ltd. for supplying the ArF excimer laser system. This work was partly supported by HBF grant of Hoso-Bunka Foundation, Inc.

'P. Hansen and J.-P. Krumme, Thin Solid Films 69, 114 (1984).

${ }^{2}$ C. Vittoria, P. Lubitz, P. Hansen, and W. Tolksdorf, J. Appl. Phys. 57 3699 (1985).

${ }^{3}$ T. Okuda, N. Koshizuka, K. Hayashi, T. Takahashi, H. Kotani, and $\mathrm{H}$ Yamamoto, J. Magn. Soc. Jpn. Suppl, No. S1, 179 (1987).

${ }^{4}$ T. Okuda, N. Koshizuka, K. Hayashi, T. Takahashi, H. Kotani, and H. Yamamoto, IEEE Trans. Magn. 23, 3491 (1987)

${ }^{5}$ M. Gomi, T. Tanida, and M. Abe, J. Appl. Phys. 57, 3888 (1985).

6. J.P. Krumme, V. Doormann, and P. Willich, J. Appl. Phys. 57, 3885 (1985).

${ }^{7}$ R. Nawathey, R. D. Vispute, S. M. Chaudhari, S. M. Kanetkar, and S B. Ogale, Solid State Commun. 71, 9 (1989).

${ }^{8}$ G. M. Davis and M. C. Gowe, Appl. Phys. Lett. 55, 112 (1989).

${ }^{9}$ R. Ramesh, K. Luther, B. Wilkens, D. L. Hart, E. Wang, and J. M Tarascon, Appl. Phys. Lett. 57, 1505 (1990).

${ }^{10} \mathrm{~S}$. Otsubo, T. Minamikawa, Y, Yonezawa, T. Maeda, A. Moto, A Morimoto, and T. Shimizu, Jpn. J. Appl. Phys. 27, L1999 (1988)

${ }^{1}$ S. Otsubo, T. Minamikawa, Y. Yonezawa, T. Maeda, A. Morimoto and T. Shimizu, Jpn. J. Appl. Phys. 28, 2211 (1989).

${ }^{12}$ S. Otsubo, T. Maeda, T. Minamikawa, Y. Yonezawa, A. Morimoto, and T. Shimizu. Jpn. J. Appl. Phys. 29, L133 (1989)

${ }^{13}$ A. Morimoto, S. Otsubo, T. Shimizu, T. Minamikawa, Y. Yonezawa, H. Kidoh, and T. Ogawa, Mater. Res. Soc. Symp. Proc. 191, 31 (1990).

${ }^{14}$ T. Okuda, T. Katayama, H. Kobayashi, N. Kobayashi, K. Satoh, and H. Yamamoto, J. Appl. Phys. 67, 4944 (1990). 